\title{
Effects of Various Drugs on Activity of the Neuronally Isolated Cerebral Cortex
}

\author{
Richard H. Rech and Edward F. Domino ${ }^{1}$ \\ Department of Pharmacology, University of Michigan Medical School, Ann Arbor, \\ Michigan
}

Received March 11, 1960

\begin{abstract}
The topical application of strychnine, $d$-tubocurarine, pentylenetetrazole, picrotoxin, and physostigmine evoked different patterns of electrical activity in a portion of the acutely isolated suprasylvian gyrus of dogs. Pentylenetetrazole and picrotoxin evoked a similar pattern of activity in the isolated gyrus by both topical application and intravenous administration. Reasonable systemic doses of strychnine, $d$-tubocurarine and physostigmine did not produce activity similar to that seen on topical application. Therefore, the effects obtained by topical application of drugs to the cerebral cortex must be interpreted cautiously as regarding the usual pharmacological actions of these agents. Adrenergic agents, administered systemically, exerted a diphasic effect upon chemically and electrically evoked activity. An initial depression and subsequent enhancement were observed. These actions were exceedingly variable and did not appear to be secondary to vascular effects. On the other hand the effects of acetylcholine and arecoline did seem to be secondary to their cardiovascular effects. Since entirely different patterns of spontaneous and evoked electrical activity could be recorded simultaneously from the isolated and nearby intact portions of the cortex, it was concluded that the neuronally isolated cerebral cortex gave rise to independent activity.
\end{abstract}

\section{Introduction}

The neuronally isolated cerebral cortex has been studied extensively by Burns and his collaborators (2). They found the isolated cerebral cortex of the cat was electrically silent, but were able to evoke potentials by direct electrical stimulation. Single weak shocks produced a surface negative wave identical to that seen in the intact cortex by Adrian (1). A stronger stimulus evoked a secondary surface positive wave with oscilla-

1 Supported in part by a grant, B-1311 (C1-C2), from the United States Public Health Service. Dr. R. H. Rech, whose present address is, Department of Pharmacology, University of Utah Medical School, Salt Lake City, Utah, held predoctoral research fellowship No. MF9406, United States Public Health Service. 
tions occurring at the nadir. This latter response was named the burst response by Burns and propagated throughout the island of cortex without decrementing. It was identified with activity in a neuronal net located in the fourth and fifth cortical layers. As described by Adrian for the intact cortex, repetitive stimuli evoked an afterdischarge in the isolated region.

Other investigators $(3,4,5,6,8,10,11,17)$ reported that the isolated cerebral cortex exhibited spontaneous electrical activity. They also determined the effects of various pharmacological agents upon the electrical activity of this preparation. The agents were tested by topical application to the isolated cortical area or by systemic administration. Usually the effects of one or two substances were determined, and often no attempt was made to compare effects induced by topical application with those following systemic injection.

The present investigation attempted to study in more detail the types of electrical activity induced in the isolated cortex in response to the administration of stimulant drugs and the modification of activity by depressant agents. Moreover, comparison was made between effects of these substances obtained by topical application and those following systemic injection.

\section{Methods}

Mongrel dogs of either sex were anesthetized with intravenous thiopental $(30 \mathrm{mg} / \mathrm{kg})$ and were maintained with subsequent increments $(5 \mathrm{mg} / \mathrm{kg})$ for the duration of surgery. Only rarely was more than a total of $35 \mathrm{mg}$ per kilogram necessary. The trachea was intubated and the femoral vein cannulated for injections. In some experiments, the femoral artery also was cannulated for recording of blood pressure with a mercury manometer. The carotid artery was cannulated with a loop of polyethylene and rubber tubing for intracarotid injections. The ends of the polyethylene tubing were placed into the proximal and distal segments of the severed carotid artery. The center portion of the loop was made of rubber tubing to facilitate injection of solutions. Adequate heparinization was necessary to avoid clotting. The head of the animal was then rigidly fixed in a metal frame. The technique of isolation of the portion of cerebral cortex was similar to that of Hendershot and Chenoweth (8), except that the isolation was limited to the suprasylvian gyrus (Fig. 1) as described for the cat by Kristiansen and Courtois (11) and Domino (6). The isolated region in the present study was approximately $25 \mathrm{~mm}$ 
long, $8 \mathrm{~mm}$ wide, and $6 \mathrm{~mm}$ deep. After completion of surgery procaine $(2 \%)$ was infiltrated into all wound edges, decamethonium $(500 \mu \mathrm{g} / \mathrm{kg})$ was administered intravenously, and the animal placed on artificial respiration. Visual inspection of chest excursions and the color of the arterial blood was used to determine the adequacy of ventilation. At least

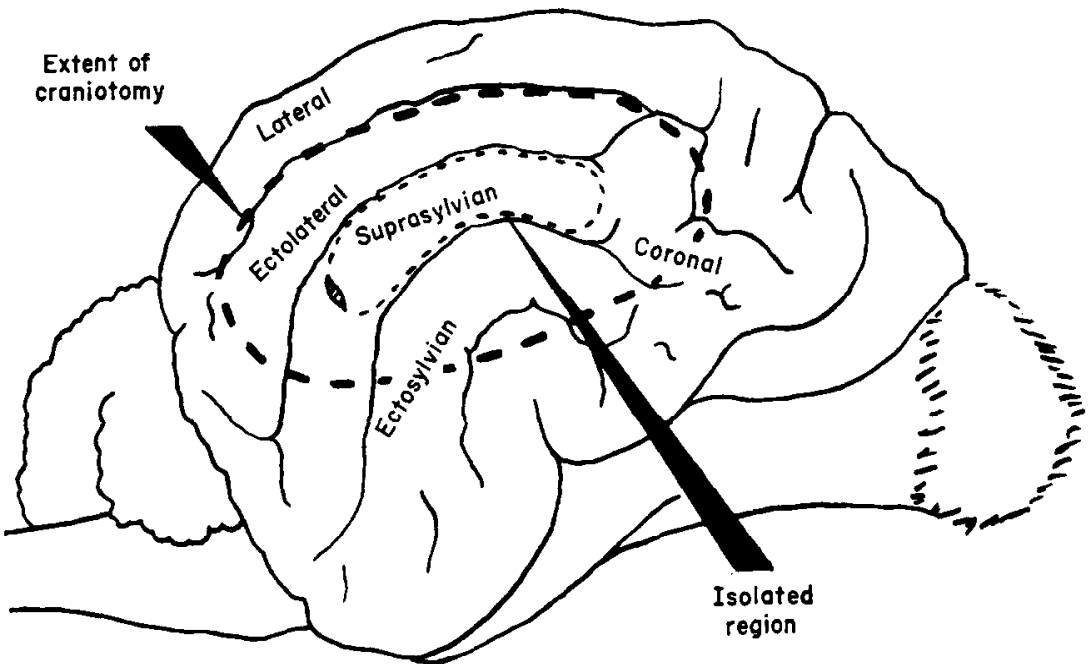

FIg. 1. Area of the dog cerebral cortex usually isolated. Modified drawing, after Miller (15).

2 hours elapsed between administration of the first dose of thiopental and the study of drug effects. The extent of recovery from anesthesia was judged by the pattern of the EEG recorded from intact cortical areas. Neuromuscular blockade was maintained for the duration of the experiment with intravenous injections of decamethonium $(250 \mu \mathrm{g} / \mathrm{kg})$ as needed.

An 8 channel Grass Model IIIC electroencephalograph recorded the electrocorticogram of the isolated and surrounding intact cortical areas. The recording electrodes consisted of silver wire wound around cotton wicks soaked in saline. Recordings were usually monopolar, although some bipolar records were taken. The indifferent electrode consisted of a needle inserted into a crushed portion of the exposed temporal muscle. Afterdischarge in the isolated gyrus in response to repetitive electrical stimuli was also recorded on the EEG. Monophasic square wave pulses of 0.5 to $1 \mathrm{msec}, 10$ to 50 per second, and of a total duration of 3 to 10 
seconds, were delivered bipolarly to one end of the isolated region by an American Electronics Laboratory, Type 104, stimulator.

Drugs were applied topically by means of $2-\mathrm{mm}^{2}$ pieces of filter paper saturated with a solution of the desired agent and placed on the cortex beneath a recording electrode. The solutions thus applied were adjusted as closely as possible to a $\mathrm{pH}$ of 7 and an osmolarity equivalent to 0.9 per cent saline solution.

Histological studies were performed in approximately 10 per cent of the preparations. Sections were cut coronally through a portion of the hemisphere containing the isolated gyrus and stained with thionine, or hematoxylin and eosin. ${ }^{2}$

\section{Results}

The spontaneous electrical activity observed in the isolated and nearby intact cortical areas before and after partial recovery from thiopental anesthesia is illustrated in Fig. 2. The EEG tracings in panel A reflect the effects of the anesthetic $20 \mathrm{~min}$ after completion of surgery. The amplitude of the waves from the isolated region was usually 60 to 80 per cent that of surrounding areas. In panel B, 40 min later, partial recovery from anesthesia was indicated by the low-voltage, fast frequency pattern in the intact cortical areas. The isolated portion still showed high-voltage waves; but intermittent low-voltage "bursts" preceded some of them. This pattern of activity has been previously observed in acutely and chronically isolated cerebral cortex of several species $(7,9,10)$ and has been called "suppression bursts."

Strychnine sulfate was applied topically to the isolated cerebral cortex of twenty-eight animals in concentrations of 0.1 to 1.0 per cent. The lowest concentration produced small negative spikes at irregular intervals. Intermediate concentrations $(0.25-0.5 \%)$ caused the appearance of larger diphasic spikes (negative-positive), 0.4 to $1 \mathrm{mv}$ in amplitude. These occurred at regular intervals, increasing in frequency as the amplitude increased. A triphasic pattern (positive-negative-positive), 1 to $2.5 \mathrm{mv}$, appeared after application of the highest concentration of strychnine. The negative phase of these complexes decreased with distance along the cortex from the focus for 5 to $10 \mathrm{~mm}$. The activity induced by one application of strychnine usually lasted about $15 \mathrm{~min}$. Several applications of strychnine $(1 \%)$ to the same area led to a characteristic sequence of

2 The authors would like to acknowledge the assistance of Miss Kathleen Lathers in performing the histology. 
repetitive discharge, as illustrated in Fig. 3 . The spiking frequency increased and small oscillations were observed to follow the larger spikes (Fig. 3A). This "burst" consisted of 4 to 8 small spikes 0.4 to $0.6 \mathrm{mv}$ in amplitude at a frequency of 12 to 24 per sec. As the activity became more intense the initial spike was enhanced and the pattern of the burst

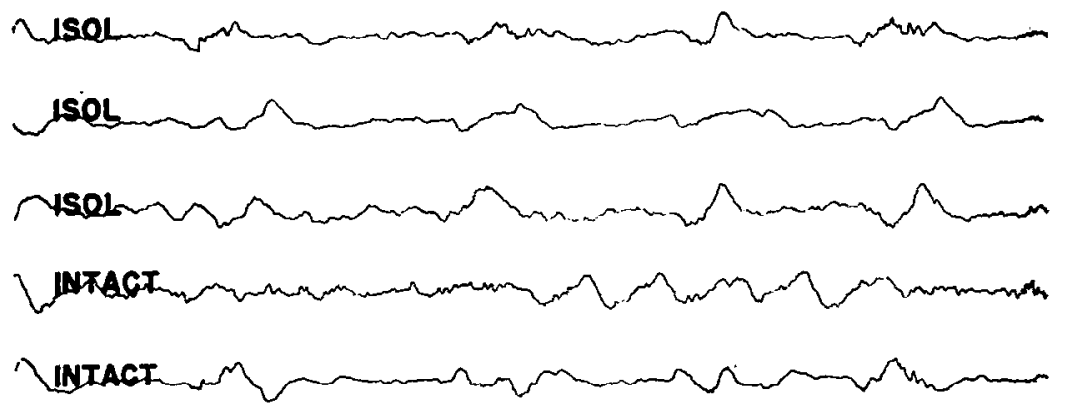

A
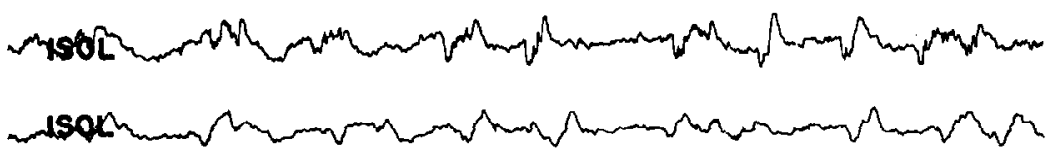

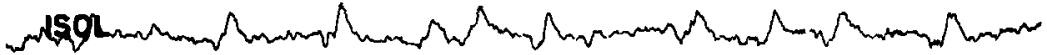

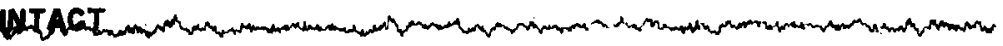

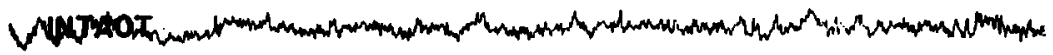

B

DOG $58200 \mu \mathrm{VV} \mathrm{L}_{\text {SEC }}$

FIG. 2. Spontaneous electrical activity in the cerebral cortex. A, isolated $15 \mathrm{~min}$, and intact, while the animal was under the effects of thiopental. B, when animal had partially recovered from anesthesia, 1 hour after isolation. All recordings in this and subsequent figures are monopolar.

was altered (Fig. 3B). An electrical seizure usually occurred shortly thereafter (Fig. 3C), followed by a relatively silent period related in duration to the length of the seizure. Subsequently there was a repetition of the phases described above. As the seizure episodes increased in length, areas of the isolated region near the focus of activity were gradu- 
ally involved (Fig. 3D, E). During this period the two leads from the nearby intact cortex, shown in Fig. $3 \mathrm{E}$, exhibited an intense low voltage, fast frequency pattern. The intravenous injection of atropine sulfate $(0.5-1.0 \mathrm{mg} / \mathrm{kg})$ did not affect the electrical activity induced by strychnine.

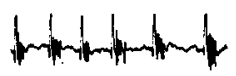

A

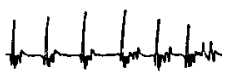

B

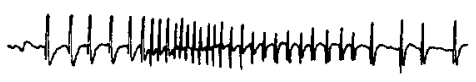

C

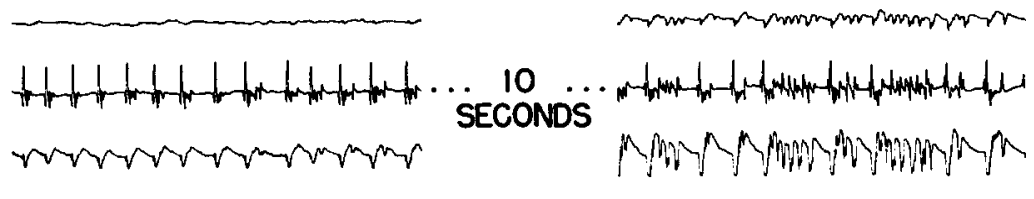

D

MIACL

LITACI

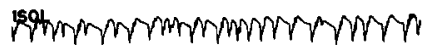

satpminommompmpmom

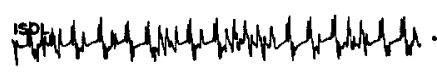

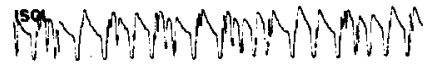

SECONDS 10 .

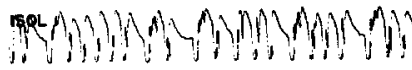

NIACT

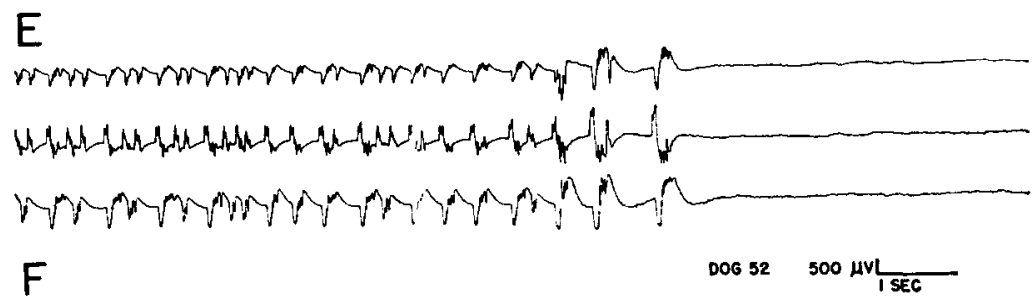

FIG. 3. Development of EEG seizures following repeated topical application of $1 \%$ strychnine. See text.

Strychnine applied to the intact cortical regions induced activity which differed from that described above. The diphasic and triphasic spikes were similar in shape but much smaller in amplitude and more frequent. Moreover, no "burst" followed the triphasic spike, and the electrical seizures produced were made up of smaller, more regular, and more frequent components than those which occurred in the isolated area. The paroxysm spread for a variable distance of several centimeters across the 
regions with intact pathways. Seizures induced simultaneously in the isolated and surrounding intact areas were independent. However, if a bridge of filter paper saturated with the drug connected the two foci, some phasic relationships developed.

Intravenous injections of strychnine produced large triphasic spikes in the isolated gyrus and nearby areas only in supraconvulsant doses of $1 \mathrm{mg}$ per kg. Accompanying this effect was a marked increase in arterial blood pressure. In two animals injected with this dose of strychnine, the increase in blood pressure was great enough to burst open many of the vessels occluded with clots around the craniotomy and cause massive hemorrhage. After a few minutes, recording of cortical potentials was no longer possible. Therefore, further experiments of this type were abandoned.

The activity induced in the isolated and intact cortex by topical application of $d$-tubocurarine hydrochloride was very similar to that evoked by strychnine, although the former agent was five times as potent. Twelve animals were studied. The intravenous administration of $d$-tubocurarine in doses up to $1 \mathrm{mg}$ per kilogram had no effect on the activity of the isolated or intact cortex. One per cent solutions of other agents which are active at peripheral "nicotinic" sites (decamethonium, gallamine, hexamethonium, and mecamylamine), when applied to the isolated area, were ineffective in altering its activity.

Pentylenetetrazole, applied in solution $(5 \%)$ to the isolated cortex of nine animals, induced a variable number of EEG seizures for 10 to 15 min. Isolated triphasic spikes similar to those described for strychnine usually preceded the seizures. Several applications of the drug caused the hyperactivity to spread from the focus to all portions of the isolated region. The electrical seizure pattern in response to this agent (Fig. 4A) was different from that of strychnine with small spikes and waves alternating. As with strychnine, pentylenetetrazole applied to discrete loci of the isolated area and surrounding intact region produced seizures which were completely independent. A bridge of filter paper, soaked in the drug solution and placed across the section, caused some phasic relationships to develop. Intravenous injections of pentylenetetrazole $(10 \mathrm{mg} / \mathrm{kg})$ were followed by high-voltage slow waves in all cortical leads lasting for 5 to $10 \mathrm{~min}$. Increasing the dose to $20 \mathrm{mg}$ per kilogram produced occasional spikes interspersed among the high-voltage waves in the isolated portion, but the activity in the intact cortex changed to an intense low voltage, fast frequency pattern. Thirty mg per kilogram of the agent precipitated 
electrical seizures in all cortical areas as illustrated in Fig. 4C. Although the activity was not completely synchronous, it was initiated and ceased about the same time in all leads. During the postictal period the intact regions were completely isoelectric, but the isolated gyrus displayed low amplitude slow waves.

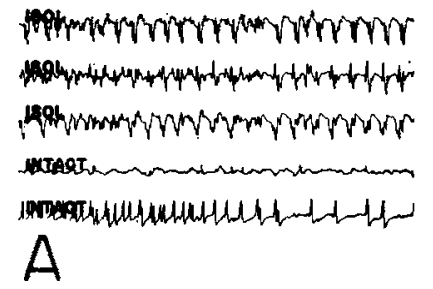

ONSET

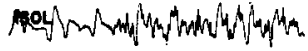

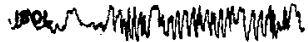

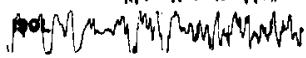

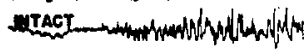

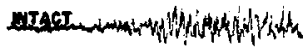
C

ONSET

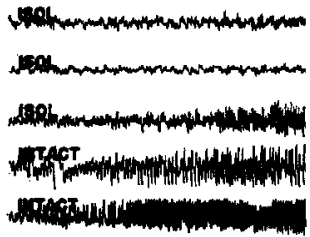

D
30 SEC LATER
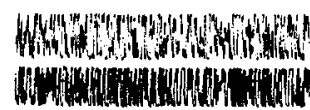

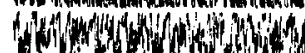

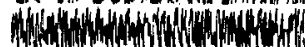

Why

30 SEC LATER

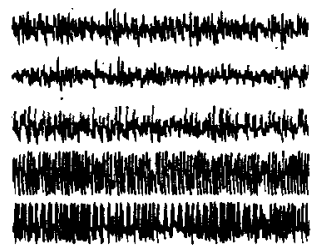

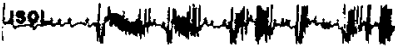

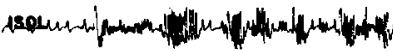

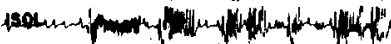

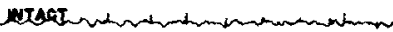

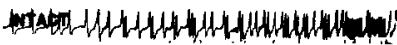

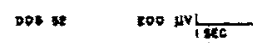

2 MIN LATER

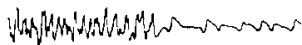

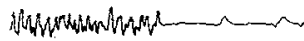

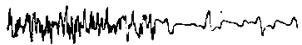

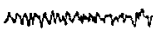

$00040 \quad 2004 \mathrm{nV} / \mathrm{Lec}$

3 MIN LATER

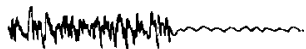

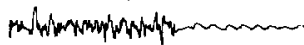

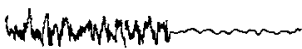

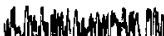

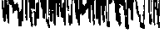

WHAWMWWWWH

000 so $200 \mathrm{ur}$

FIc, 4. Seizures produced by pentylenetetrazole (A and C) and picrotoxin (B and $D$ ). In $A$ and $B$, the agents were applied topically to portions of the cerebral cortex recorded in channels 1 and 5 ; in $C$ and $D$, they were injected intravenously. See text.

Topical application of picrotoxin (0.1-0.25\%) evoked electrical seizures in the isolated cortex of nine animals which were different from those due to strychnine or pentylenetetrazole. Within $4 \mathrm{~min}$, diphasic spikes were observed which quickly developed into a triphasic pattern and then into a seizure, as illustrated in Fig. 4B. Groups of high-frequency spikes were separated by brief periods of lesser activity. Longer 
periods of postictal depression followed a series of these complexes. After just one application of picrotoxin the intermittent seizures spread throughout the entire isolated area and continued for 3 hours or more. The pattern of activity in the intact cortex brought about by the application of this agent was similar to that due to strychnine or pentylenetetrazole. Seizure foci induced simultaneously in the isolated and nearby intact regions exhibited patterns which were unrelated. A bridge of filter paper saturated with the drug caused some phasic relationships between these foci. Intravenous picrotoxin in doses of 0.5 to $1.5 \mathrm{mg}$ per kilogram gave rise to discharges in all cortical areas 10 to $15 \mathrm{~min}$ after injection. These are shown in Fig. 4D. Prior to the seizure, all leads developed low voltage, fast frequency rhythms occasionally interrupted by large spikes. As in the case of pentylenetetrazole, low voltage slow waves occurred in the isolated area during the postictal period.

Physostigmine salicylate $(0.25-1.0 \%)$ was applied topically to the isolated cerebral cortex of fifteen animals. Low concentrations caused a marked increase in frequency and reduction in amplitude of the spontaneous electrical activity. High concentrations produced in addition an increase in amplitude amounting to 0.4 to $0.8 \mathrm{mv}$. When physostigmine $(50-200 \mu \mathrm{g} / \mathrm{kg}$ ) was injected intravenously, the intact cortex developed a very flat fast frequency electrical pattern. However, the activity of the isolated gyrus was not appreciably altered, although occasionally the amplitude of the large slow waves increased.

The application of physostigmine $(1.0 \%)$ to an area of the isolated cortex manifesting typical strychnine spikes (Fig. 5A) converted these to a seizure within $5 \mathrm{~min}$, as seen in Fig. 5B. This seizure was different in its pattern from that induced by strychnine alone or by other agents. Within a few minutes after the intravenous injection of atropine sulfate $(0.5-1.0 \mathrm{mg} / \mathrm{kg})$, the electrical seizure ceased and single strychnine spikes reappeared (Fig. 5C). All of the other effects of physostigmine as described above were also antagonized by atropine. Intravenous physostigmine in doses of 100 to $200 \mu \mathrm{g}$ per kilogram did not significantly alter strychnine spikes in the isolated gyrus.

The intravenous or intracarotid injection of the cholinergic agents acetylcholine, arecoline, and nicotine transiently decreased the frequency of strychnine or $d$-tubocurarine spiking in the isolated cortex of eight animals. The doses used were the following: acetylcholine hydrochloride, 2 to $6 \mu \mathrm{g}$ per kilogram; arecoline hydrochloride, 10 to $20 \mu \mathrm{g}$ per kilogram; and nicotine, 10 to $20 \mu \mathrm{g}$ per kilogram. All agents produced marked 
cardiovascular changes. The intravenous administration of atropine methyl nitrate or atropine sulfate $(0.5-1.0 \mathrm{mg} / \mathrm{kg})$ abolished both the cardiovascular effects and slowing of the spiking frequency due to acetylcholine and arecoline. Atropine methyl nitrate, within $30 \mathrm{~min}$ after injection, did not cause the characteristic slowing of the EEG produced by

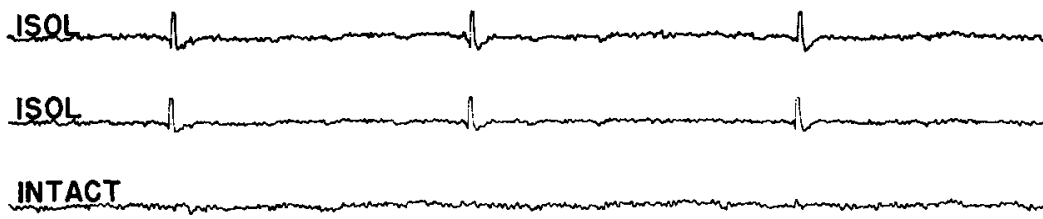

\section{A}
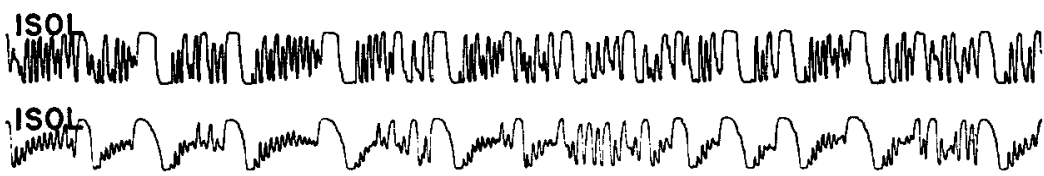

INTACT

B

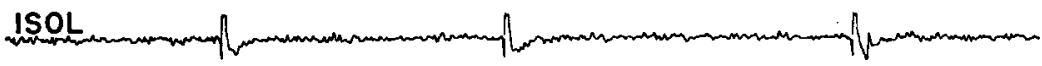

ISOL

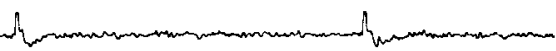

INTAGT

C

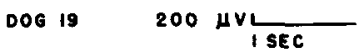

FIG. 5. Effect of topical application of $1 \%$ physostigmine, $\mathbf{B}$, to an isolated cortical area exhibiting strychnine spikes, A. Atropine, intravenously, in C. See text.

atropine. Because atropine produced slowing of the EEG and methyl atropine did not, it was concluded that atropine had the greater central effect. Since both agents were equally effective in preventing the modifications induced by acetylcholine and arecoline, it was assumed the latter phenomena were secondary to cardiovascular effects.

The frequency of strychnine or $d$-tubocurarine spiking in the isolated cortical area of fifteen animals was decreased after intravenous or intra- 
carotid epinephrine, norepinephrine, or serotonin. The effect was most marked and reproducible with 2 to $\sigma \mu \mathrm{g}$ per kilogram of epinephrine, more variable with 20 to $60 \mu \mathrm{g}$ per kilogram of serotonin, and least reproducible with 2 to $6 \mu \mathrm{g}$ per kilogram of norepinephrine. Even with epinephrine, the response was quite variable. The hypertensive effect was greatest with norepinephrine, less with epinephrine, and least with serotonin. Following the intravenous administration of $2 \mathrm{mg}$ per kilogram of phenoxybenzamine (Dibenzyline), the depression of the spiking frequency by epinephrine was enhanced in intensity and duration. Intravenous isoproterenol $(2-4 \mu \mathrm{g} / \mathrm{kg})$ caused a severe fall in blood pressure for several minutes. Spiking in the isolated region was usually abolished during this period. As the blood pressure returned to normal the isolated area often exhibited an electrical seizure. This was followed by postictal depression and, eventually, return of the spikes. After a series of injections of epinephrine the susceptibility of the isolated region to electrical seizures in response to chemical agents appeared to be greatly increased. The effects of epinephrine were also investigated in six animals on the afterdischarge in the isolated area in response to repetitive electrical stimulation. The intracarotid injection of 1 to $2 \mu \mathrm{g}$ per kilogram just prior to electrical stimulation depressed the afterdischarge. Recovery occurred gradually over the next $10 \mathrm{~min}$. After a total of four to six injections of epinephrine the duration of afterdischarge increased as compared to control, even though it was reduced immediately after each injection. Considerable animal variation was observed.

Microscopical examination of semiserial sections through the isolated and surrounding normal cortex showed that all nerve fibers to the island were severed with the exception of small filaments in the molecular layer. A typical section is pictured in Fig. 6. It was observed, especially using hematoxylin and eosin, that neurons and fibers bordering the surgical section showed degenerative changes, whereas the cortical gray matter in the center of the isolated region was normal in appearance. These findings suggest that either the surgical trauma or the diminished cortical blood supply destroys the edges of the isolated cortex.

\section{Discussion}

The isolated cerebral cortex preparation of the dog appears to be suitable for studying the cortical actions of pharmacological agents. Chemically evoked activity, may be confined to the isolated gyrus or a limited portion of the intact cortex by topical application of the agent to a small 
area. Systemic administration of pentylenetetrazole or picrotoxin induced effects in the isolated region comparable to those seen after topical application. Pentylenetetrazole applied in a high concentration or injected intravenously in a large dose produced initially high voltage slow waves and subsequently electrical seizures of 5 to $15 \mathrm{~min}$ duration. On the other

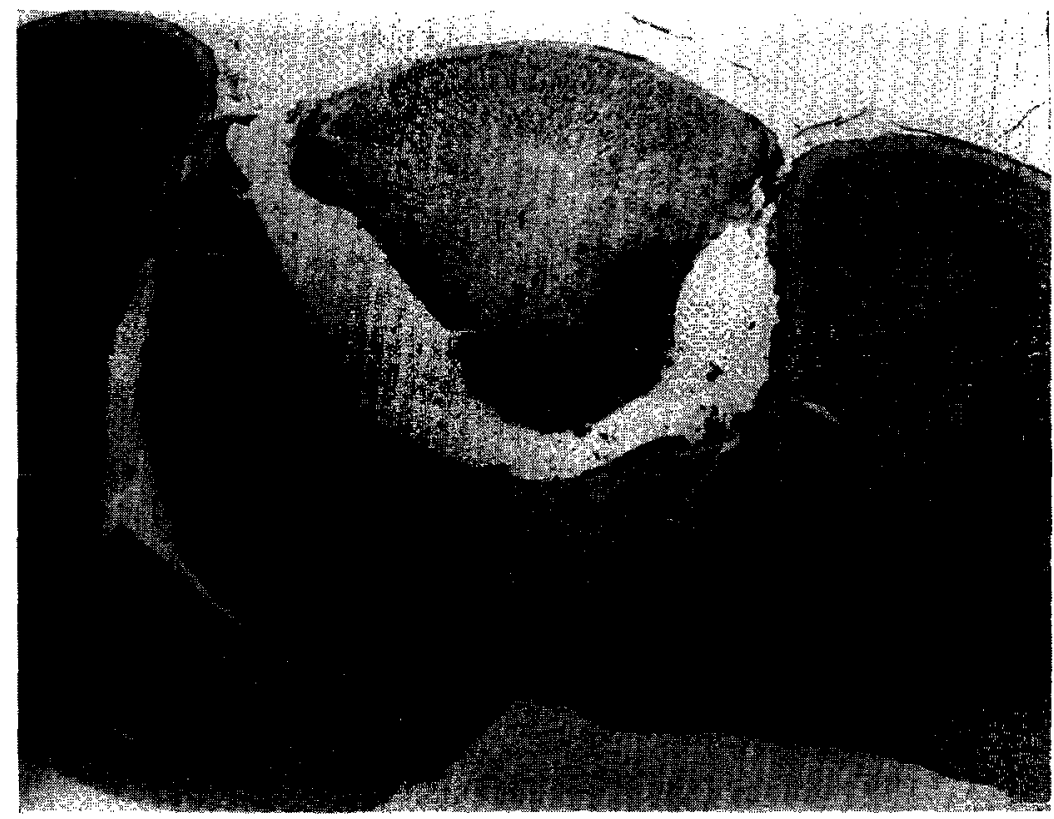

FIG. 6. Photomicrograph of a ccronal section through the isolated cerebral cortex; thionine; approximately $8 \times$.

hand, picrotoxin applied in a low concentration or injected intravenously in a small dose induced prolonged EEG seizures without prior high voltage slow waves. The conclusion of Preston (17) that pentylenetetrazole has a direct cortical action in cats appears to be valid in dogs as well. It is of interest that although both pentylenetetrazole and picrotoxin caused electrical seizures in the isolated cortex, the seizures were of greater amplitude following pentylenetetrazole. The characteristic lag period following systemic administration of picrotoxin was shortened with topical application.

Not all agents applied topically were effective systemically in reasonable doses, as shown by the effects observed after the administration of 
strychnine, $d$-tubocurarine, and physostigmine. This lack of correlation between topical and systemic administration, among other factors, is undoubtedly related to the absolute concentration of the agent attained in the isolated region by the several routes, its capacity to penetrate the blood-brain barrier, cortical-subcortical interactions, and other less obvious factors. After systemic administration of physostigmine, the slow waves in the isolated gyrus were increased in amplitude, while the intact cortex showed intense EEG activation. These results support the hypothesis of Rinaldi and Himwich (18) concerning a possible cholinergic brain-stem mechanism for EEG arousal. The low voltage, fast frequency pattern induced in an isolated or intact cortical area by topical physostigmine may indicate a cholinergic system in the cortex for EEG activation. In support of this suggestion was the antagonism of this activation by intravenously administered atropine. On the other hand, the stimulant effects of $d$-tubocurarine when applied to the cortex probably cannot be explained on the basis of its "nicotinic" blocking properties, inasmuch as decamethonium, gallamine, hexamethonium, and mecamylamine were ineffective. Therefore, it is wise to exercise extreme caution in the interpretation of results obtained through the topical application of substances to the cerebral cortex. Possible alteration of intra- or extracellular $\mathrm{pH}$ of the cortical area, alteration of the pial blood flow, or irritant, injurious, or local anesthetic effects due to the abnormally high concentration of the agent applied might account for some types of activity observed.

With proper controls evoking activity in the cerebral cortex by the topical application of drugs is especially justified in a study of cortical mechanisms. According to McCulloch (14), a chemical stimulant may be expected to excite cell systems or types of neurons more specifically than electrical stimulation. This assumption appears to be validated by the results of the present investigation, since different electrical patterns are induced in the isolated cerebral cortex by the application of strychnine, pentylenetetrazole, picrotoxin, and physostigmine.

The failure of Wright, Andrew, and Jacobson (19) to obscrve strychnine spikes or spontaneous activity in the isolated cortex of cats is probably related to the use of pentobarbital anesthesia rather than a species difference. The burst following the large triphasic strychnine spike as a prelude to hypersynchronous activity in the isolated region may relate to the initiation and spread of electrical seizures. Further investigation to determine whether this phenomenon is similar to the burst response observed in the cat isolated cortex by Burns would be of advantage. 
Burns identified this burst response with activity in a neuron net in the fourth and fifth layers of the cortex. Since this burst spread throughout the isolated region without decrementing, he presumed this neuron net to be important in the spread of activity from one cortical area to another.

The effect of adrenergic agents in depressing the strychnine spiking frequency in the isolated gyrus apparently cannot be related altogether to arterial blood pressure changes. Norepinephrine caused the greatest change in blood pressure, but epinephrine was most active in altering the spiking frequency. Serotonin, which produced the least effect on blood pressure, was almost as effective as epinephrine in slowing the spiking frequency. Prior treatment of the animal with phenoxybenzamine converted the pressor response of epinephrine to a depressor one but enhanced the cffect on spiking frequency. An inhibition by cpinephrine of cortical neurons, at least soon after administration, also is indicated by its depression of electrically evoked afterdischarge. Perhaps these depressant actions of epinephrine and serotonin are related to the inhibition of the transcallosal response by these drugs, as reported by Marrazzi (12) and Marrazzi and Hart (13). In any event, the action of these agents on spiking frequency was quite variable and often not significant. As described by Minz and Domino (16) for the intact cortex, a series of injections of epinephrine was found to prolong afterdischarge evoked in the isolated cortex by repetitive electrical stimulation. In addition, the susceptibility of the isolated region to chemically induced seizures was greatly increased after administering epinephrine several times. This agent does seem to have a delayed capacity to increase the excitability of cortical neurons. Again these effects were quite variable and difficult to reproduce in all animals.

As described above, the isolated cerebral cortex of the dog exhibited spontaneous electrical activity. This activity could not have been due to electrical pickup from the surrounding normal cortex since these areas produced entirely different patterns of potentials under a variety of conditions. It appears unlikely that the activity in the isolated region was due to injury potentials, since it persisted for at least 6 to 14 hours, and injury potentials usually subside within a shorter period of time. If the activities in the isolated and intact portions of the cortex were closely related, seizures induced in these regions simultaneously should have been phasically related. On the contrary, these seizure patterns were found to be independent. Considering these results, it seems justified to conclude that the isolated cerebral cortex of the dog is capable of inherent electrical activity. 


\section{References}

1. Adrian, E. D., The spread of activity in the cerebral cortex. J. Physiol. (London) 88: 127-161, 1936.

2. Burns, B. D., "The Mammalian Cerebral Cortex." London, Edward Arnold Ltd., 1958.

3. Crepax, P., and F. Infantellina, Azione della morfina sul lembo isolato di corteccia cerebrale di gatto. Arch. sci. biol. (Bologna) 40: 147-162, 1956.

4. Crepax, P., and F. Infantellina, Azione della 5-idrossitriptamina sull 'attività elettrica della corteccia cerebrale di gatto. Arch. sci. biol. (Bologna) 41: 207232, 1957.

5. Crepax, P., and F. Infantellina, Effetti dell 'applicazione locale di morfina sull 'attività elettrica del lembo isolato di corteccia cerebrale di cane predisposto ovvero non predisposto alla epilessia riflessa. Arch. sci. biol. (Bologna) 42: 415-432, 1958.

6. Domino, E. F., Pharmacological actions of a convulsant barbiturate II. Effects compared with pentobarbital on cerebral cortex and some brain stem systems of the cat. J. Pharmacol. Exp. Therap. 119: 272-283, 1957.

7. Echlin, F. A., V. Arvetr, and J. Zoll, Paroxysmal high voltage discharges from isolated and partially isolated human and animal ceerbral cortex. Electroencephalog. and Clin. Neurophysiol. 4: 147-164, 1952.

8. Hendershot, L. C., and M. B. Chenoweth, Fluoroacetate and fluorobutyrate convulsions in the isolated cerebral cortex of the dog. J. Pharmacol Exp. Therap. 113: 160-168, 1955.

9. Henry, C. E., and W. B. Scoville, Suppression-burst activity from isolated cerebral cortex in man. Electroencephalog. and Clin. Neurnphysiol. 4: 1-22, 1952.

10. INGVAR, D. H., Electrical activity of isolated cortex in the unanesthetized cat with intact brain stem. Acta Physiol. Scand. 33: 151-168, 1955.

11. Kristiansen, K., and G. Courtois, Rhythmic electrical activity from isolated cerebral cortex. Electroencephalog. and Clin. Neurophysiol. 1: 265-272, 1949.

12. Marrazzi, A. S., "The Biology cf Mental Health and Disease," pp. 376-384, New York, Hoeber, 1952.

13. Marrazzi, A. S., and E. R. Hart, Relationship of hallucinogens to adrenergic cerebral neurohumors. Science 121: 365-367, 1955.

14. McCuldoch, W. S., The functional nrganization of the cerebral cortex. Physiol. Rev. 24: 390-407, 1944.

15. Miller, M. E., "Guide to the Dissection of the Dog," 3rd ed., p. 316; Ithaca, N.Y., 1952 (Lithoprinted by Edwards Brothers, Ann Arbor, Michigan).

16. Minz, B., and E. F. Domino, Effects of epinephrine and norepinephrine on electrically induced seizures. J. Pharmacol. Exp. Therap. 107: 204-218, 1953.

17. Preston, J. B., Pentylenetetrazole and thiosemicarbazide: A study of convulsant activity in the isolated ceerbral cortex preparation. J. Pharmacol. Exp. Therap. 115: 28-38, 1955.

18. Rinaldi, F., and H. E. Hrmwich, Cholinergic mechanism involved in the function of mesodiencephalic activating system. A.M.A. Arch. Neurol. Psychiat. 73: 396-409, 1955.

19. Wright, M. K., W. K. AndRew, and I. JACOBSON, Observations on strychninised isolated cortex. Electroencephalog. and Clin. Neurophysiol. 6: 635-642, 1954. 